\title{
Validity and reliability of two brief physical activity questionnaires among Spanish-speaking individuals of Mexican descent
}

\author{
Sonia Vega-López ${ }^{*}$, Adrian Chavez, Kristin J Farr and Barbara E Ainsworth
}

\begin{abstract}
Background: Mexican Americans are the largest minority group in the US and suffer disproportionate rates of diseases related to the lack of physical activity (PA). Since many of these Mexican Americans are Spanish-speaking, it is important to validate a Spanish language physical activity assessment tool that can be used in epidemiology as well as clinical practice. This study explored the utility of two Spanish translated physical activity questionnaires, the Stanford Brief Activity Survey (SBAS) and the Rapid Assessment of Physical Activity (RAPA), for use among Spanish-speaking Mexican Americans.
\end{abstract}

Methods: Thirty-four participants (13 M, 21 F; $37.6 \pm 9.5$ y) completed each of the two PA surveys twice, one week apart. During that week 31 participants also wore an ActiGraph GT1M accelerometer for 7 days to objectively measure PA. Minutes of moderate and vigorous PA (MVPA) were determined from the accelerometer data using Freedson and Matthews cut points.

Results: Validity, determined by Spearman correlation coefficients between questionnaire scores and minutes of ActiGraph measured MVPA were 0.38 and 0.45 for the SBAS and RAPA, respectively. Test-retest reliability was 0.61 for the SBAS and 0.65 for the RAPA. Sensitivity and specificity were 0.60 and 0.47 for the SBAS, and 0.73 and 0.75 for the RAPA. Participants who were classified as meeting the 2008 National Physical Activity Guidelines by the RAPA engaged in significantly $(p<0.05)$ more minutes of MVPA than those who were not, while there were no significant differences in minutes of MVPA classified by the SBAS.

Conclusions: The SBAS and the RAPA are both reasonably valid measures for quickly assessing PA and determining compliance to the PA guidelines in Spanish-speaking Mexican Americans. Although the two questionnaires had comparable reliability, the RAPA was better able to distinguish between those who met and did not meet National PA Guidelines.

Keywords: Physical activity assessment, Validity, Reliability, Survey, Spanish

\section{Background}

Hispanics are the largest ethnic minority group in the United States constituting $16 \%$ of the population, of which $63 \%$ are of Mexican descent [1]. Relative to other ethnic groups, Mexican Americans are considered to be at increased risk for the development of chronic diseases. This is in part due to disparities in the prevalence of risk factors such as obesity [2-4], cardiovascular disease risk factors [5], inflammatory markers [6,7],

\footnotetext{
*Correspondence: sonia.vega.lopez@asu.edu

School of Nutrition and Health Promotion, Arizona State University, 500 North 3rd Street, Phoenix, AZ 85004, USA
}

insulin resistance [8], and metabolic syndrome and its components [9]. Moreover, Mexican Americans have been reported to have a higher prevalence of diabetes than non-Hispanic blacks or whites $[10,11]$. It is well established that risk factors for chronic conditions can be improved by regular physical activity (PA) [12]. In turn, low levels of PA are associated with an increased risk of mortality $[13,14]$ and risk for diabetes and cardiovascular disease $[15,16]$.

Current National PA Guidelines recommend at least 150 minutes of moderate intensity PA weekly for the adult population [17]. Recent estimates indicate that
C Biomed Central

(c) 2014 Vega-López et al.; licensee BioMed Central Ltd. This is an open access article distributed under the terms of the Creative Commons Attribution License (http://creativecommons.org/licenses/by/2.0), which permits unrestricted use, distribution, and reproduction in any medium, provided the original work is properly cited. 
many Americans are not meeting these recommendations. According to 2008 data from the National Health Interview Survey, $43.5 \%$ of all American adults met the 2008 PA guidelines; among Hispanics, only 33.4\% met these recommendations [18]. In most observational studies, physical activity and physical fitness are lower among Mexican Americans relative to African Americans and non-Hispanic whites [19,20].

Questionnaires are commonly used to assess PA in epidemiological research as well as clinical practice. Compared to alternative methods of assessing PA, questionnaires are short, easy to administer, and require minimal resources, making them ideal for administration to large populations or as a quick screening tool [21]. A potential disadvantage is that surveys often times focus on leisure-time PA and do not assess occupational PA. This may limit the utility of many surveys for use in a Mexican population, since previous research has shown that Mexicans, have high rates of occupational PA relative to other ethnic groups [22,23]. In a sample of 76,820 adults living in the US obtained from the NHIS (20002003), 39\% of Mexicans and 19\% of Mexican Americans reported having a physically active occupation compared to only $12 \%$ of non-Latino whites [22]. Therefore, assessing only leisure-time PA may underestimate true PA participation in this population.

Existing PA instruments validated for use with Spanish speakers [24-27] are relatively lengthy and may not be ideal for population-based research or clinical practice. For example, the Minnesota Leisure-Time PA Questionnaire (68-78 items) and the Seven-day Physical Activity Recall have been translated into Spanish [24,28], but both are interviewer administered and may take as long as 20 minutes to complete. Others rely on numeral literacy in completing the answers. For example, the International Physical Activity Questionnaire [26] is relatively short with 7 items, but requires complex mathematical calculations in recalling the number of days in a past week and then multiplying the days of activity by the average hours and minutes of participation for all of those days. Such mathematical calculations are difficult and are subject to reporting errors. In addition, these questionnaires have not been tailored for specific subgroups of the Hispanic population of the United States. Language and cultural differences may affect comprehension and interpretation of a questionnaire when administered to a diverse population, compromising the validity of the responses [27,29]. Thus, assessing the validity of short and accurate PA surveys that can be used in the Spanish speaking Mexican-American population is warranted.

The purpose of this study was to assess the validity and reliability of two physical activity surveys, The Stanford Brief Activity Survey (SBAS) [30] and the
Mexican Spanish version of the Rapid Assessment of Physical Activity (RAPA) [31], against accelerometer measured physical activity. These surveys were selected because they are both short and relatively easy to administer, making them ideal for use as brief physical activity screening tools. The RAPA has been previously translated into Mexican Spanish and is available for public use, but has not been validated with the target population. The SBAS is a unique questionnaire in that it assesses both occupational and leisure time physical activity in two questions. This questionnaire has been previously validated for use in an older English speaking population, but a Spanish language version of this questionnaire has not previously been developed or validated.

\section{Methods}

\section{Participants}

Thirty-seven Spanish-speaking self-reported Mexican or Mexican-American adults (15 males, 22 females; $21-56$ years old) free of known chronic diseases were recruited from the Phoenix metropolitan area by distributing fliers, advertisements in Hispanic serving publications, and by word of mouth. Participants were excluded if they met any of the following criteria: (a) known chronic conditions (diabetes, cardiovascular, kidney or thyroid disease, cancer, etc.), (b) following a specific diet regimen (veganism, very low carbohydrate diet, etc.), (c) inability to walk for exercise, (d) pregnancy or breastfeeding, (e) use of lipid lowering or antihypertensive medications, and (f) participation in any other research study. These criteria were used to exclude individuals who may have unusual diet due to a medical condition or self-selected dietary restrictive habits. The study was approved by the Institutional Review Board at Arizona State University, and all participants provided written informed consent prior to being enrolled in the study.

\section{Study design}

Participants attended two visits at the Nutrition Laboratory at Arizona State University. On the day of the first visit blood pressure and anthropometric measurements were taken, and a survey was administered in Spanish by a trained bilingual interviewer to collect PA (see below) and sociodemographic information. Participants were trained on the proper use of an ActiGraph GT1M accelerometer (ActiGraph, Pensacola, FL), and were instructed to wear it for 7 consecutive days starting the day after the first visit. A second visit was scheduled on the $8^{\text {th }}$ day to collect the accelerometer and readminister the PA surveys in Spanish. When this day fell on a weekend, participants were instructed to delay the start day so that the $8^{\text {th }}$ day fell on Monday.

Data from three participants were excluded from the entire analysis for non-compliance with wearing the accelerometer $(n=2$; see criteria below) and improper 
positioning of the accelerometer $(n=1)$. Therefore, thirty-four participants were included in analyses (13 males, 21 females). Data from one participant was excluded from the SBAS test re-test reliability calculations because the baseline SBAS was not completed. Accelerometer data were not available from three participants due to accelerometer malfunction; these individuals were excluded from the validity assessment analyses.

\section{Blood pressure and anthropometric measurements}

Weight (in kilograms) and body composition (as \% body fat) were measured using a Tanita body composition analyzer (Model TBF-300 A, Arlington Heights, IL). Height was measured in centimeters using a wall mounted stadiometer. Waist and hip circumferences were measured using a flexible tape measure at the umbilicus and at the largest portion of the hips, respectively. Blood pressure was taken following a 5 minute rest using an electronic sphygmomanometer (IntelliSense Blood Pressure Monitor HEM-907XL, Omron Healthcare, Kyoto City, Japan). All measurements were taken in triplicate and the mean of the three measurements was used for analyses. Body mass index (BMI) was calculated as mean weight in kilograms divided by mean height in meters squared $\left(\mathrm{kg} / \mathrm{m}^{2}\right)$.

\section{Physical activity assessment}

ActiGraph GT1M accelerometers (ActiGraph LLC, Pensacola, FL) were used to objectively measure time spent in ambulatory PA's of different intensities. The ActiGraph is a small, battery operated electronic motion solid state sensor (micro-electro-mechanical systems) designed to measure the rate and magnitude of body movement in a vertical plane (accelerations). Output data are digitized at a rate of thirty times per second with intensity data recorded in one minute epochs (sampling interval). The ActiGraph outputs data as counts per minute (cpm) that reflect: (a) the intensity of movement based on the frequency of acceleration deflections and (b) the duration of sustained period of the deflections. The ActiGraph GT1M has been validated as an accurate measure of energy expenditure when compared against the doubly labeled water method [32]. Intensity of activity was categorized based on cut-points developed from controlled laboratory experiments as follows: sedentary $(<100 \mathrm{cpm})$ [33], light $(100-759 \mathrm{cpm})$ and moderate-lifestyle activities (760-1951 cpm) [34], moderatewalking (1952-5725 cpm) and vigorous-intensity activities $(>5725 \mathrm{cpm})$ [35]. The sum of minutes per day of moderate and vigorous PA (MVPA) over the seven days of wear time was calculated using these categories.

Participants were instructed to wear the ActiGraph over the right hip for seven days during all waking hours, only removing it to perform water-related activities (e.g., bathing, swimming). The ActiGraph was programmed to capture accelerations beginning at midnight of the day the instrument was provided to the participant. As determined previously by Matthews et al. [36], to characterize activity levels with at least $80 \%$ reliability participants needed to wear the ActiGraph continuously for 3-4 days to characterize moderate-and vigorous-intensity movements. Consecutive accelerometer counts of zero for 60 minutes or longer was considered non-wear time and removed from time spent as daily wear time. Thus, $\geq 4$ days of data with counts recorded for $\geq 10$ hours $^{\bullet} \mathrm{d}^{-1}$ were required for inclusion in the database. All participants included in the final study sample met this criteria and had 7 days of at least 10 hours of recorded wear time. Time spent at each physical activity intensity level is reported as the sum over these 7 days $\left(\mathrm{min}^{\bullet} \mathrm{wk}^{-1}\right)$.

Subjective measurement of PA was assessed using the SBAS [30] and the Mexican Spanish version of the RAPA [31] to estimate usual amount and intensity of PA performed by study participants. These questionnaires were both interviewer administered to ensure comprehension and account for potential variations in literacy levels.

The Stanford Brief Activity Survey (SBAS) is a brief, two item survey designed to assess occupational and leisure-time PA levels without relying on the recall of time spent in various types of activity [30]. This twoitem questionnaire separately classifies the level of occupational and leisure-time PA performed by an individual. Each item provides examples of activities with increasing degree of intensity ranging from sedentary to high intensity activities. The SBAS rates occupational and leisuretime PA on a 5-point scale corresponding to classifications as inactive, light intensity, moderate intensity, hard intensity, and very hard intensity (rated as 1 through 5, respectively). Validation studies for an English language SBAS showed a strong, dose-response relation with minutes of moderate-intensity PA and energy expenditure $(p<0.01)$, and with cardiovascular disease risk factors (fasting glucose and insulin, triglycerides, HDL-C; $p<0.01$ ) [30], and test-retest reliability is $\mathrm{r}=0.62 \mathrm{l}(p<0.001)$ [37]. Prior to use, the SBAS was translated into Mexican Spanish by a bilingual/bicultural researcher (SV-L) and subsequently back translated by another bilingual research staff member who was not affiliated with the research team as previously recommended [38]. The Spanish version was a verbatim translation from the English version, with appropriate adjustments for accuracy and grammar. The purpose was not to introduce cultural adaptations (e.g. changing examples of activities to more culturallyrelevant ones) so that the original version of the SBAS could be used.

The Rapid Assessment of Physical Activity (RAPA) is a 9-item, self-administered questionnaire readable at the sixth grade reading level, designed to assess current 
levels of leisure-time PA in the clinical setting [31]. The first seven items capture level and intensity of leisuretime PA based on pictorial examples of a variety of light, moderate, and vigorous activities; the last two items assess strength and flexibility training. The total score of the first seven items capture the PA level in a 5-point rating as sedentary, underactive, regular underactive/light, regular underactive, and regular active (rated as 1 through 5 , respectively). In a validation study among older adults [31] the RAPA showed a positive correlation with PA level on the PA surveys from the Community Healthy Activities Model Program for Seniors (CHAMPS; $\mathrm{r}=0.48 ; \mathrm{p}<0.001$ ) [39], the Patient-centered Assessment and Counseling for Exercise (PACE; $\mathrm{r}=0.56 ; \mathrm{p}<0.001$ ) [40], and the Behavioral Risk Factor Surveillance System (BRFSS; $r=0.59$; $\mathrm{p}<0.001$ ). The publicly available Mexican Spanish version of the RAPA was used for this study (available from http://depts.washington.edu/hprc/rapa, accessed on $5 / 20 / 2013)$.

\section{Statistical analysis}

All statistical analyses were carried out using the IBM Statistical Program for the Social Sciences (SPSS) 19.0 for Windows (SPSS, Inc., Chicago, IL). Data are presented in text and tables as mean \pm standard deviation (SD). Differences were considered significant at the 0.05 alpha level.

All comparisons between accelerometer measured PA and the questionnaire-assessed PA were made using data from the first administration of the questionnaires. Criterion validity of the two questionnaires was assessed using Spearman's rank ordered correlation coefficients between the score on each of the questionnaires and the minutes of MVPA. One week test-retest reliability was determined using Intraclass Correlation Coefficients (ICC).

Sensitivity, specificity, and positive and negative predictive values were calculated by hand using accelerometer measured PA as the criterion to determine the ability of each questionnaire to predict whether or not a participant is meeting the 2008 U.S. PA guidelines [41]. Prior to conducting these analyses, data were dichotomized using the following criteria to classify participants as meeting the 2008 U.S. PA guidelines: (1) if accelerometer data indicated $\geq 150 \mathrm{~min}^{\bullet} \mathrm{wk}^{-1}$ of MVPA; (2) if SBAS score was 3 or higher (moderate, hard, or very hard level of activity) [30]; or (3) if RAPA score was 5 (regular active) [31]. T-tests were performed to determine if there were differences in MVPA among those who were classified as meeting and not meeting PA guidelines for each of the two questionnaires.

\section{Results}

Thirty-four (13 M, $21 \mathrm{~F})$ participants completed all or part of this study (Table 1). A majority of participants
Table 1 Descriptive characteristics of study participants

\begin{tabular}{|c|c|c|c|}
\hline Characteristic & n (\%) & $\begin{array}{l}\text { Mean } \pm \text { SD } \\
(n=34)\end{array}$ & $\begin{array}{l}\text { Median } \\
\text { (Interquartile range) }\end{array}$ \\
\hline \multicolumn{4}{|l|}{ Gender } \\
\hline Male & $13(38)$ & & \\
\hline Female & $21(62)$ & & \\
\hline \multicolumn{4}{|l|}{ Language } \\
\hline Bilingual & $30(88)$ & & \\
\hline Spanish only & $4(12)$ & & \\
\hline \multicolumn{4}{|l|}{ Place of birth } \\
\hline U.S. & $19(56)$ & & \\
\hline Outside U.S. & $15(44)$ & & \\
\hline \multicolumn{4}{|l|}{$\begin{array}{l}\text { Monthly } \\
\text { household } \\
\text { income }\end{array}$} \\
\hline$<\$ 1000$ & $8(23.5)$ & & \\
\hline$\$ 1000-\$ 2000$ & 7 (20.6) & & \\
\hline$\$ 2000-\$ 3000$ & 7 (20.6) & & \\
\hline$\$ 3000-\$ 4000$ & $4(11.8)$ & & \\
\hline$>\$ 4000$ & $7(20.6)$ & & \\
\hline \multicolumn{4}{|l|}{$\begin{array}{l}\text { Education (highest } \\
\text { level completed) }\end{array}$} \\
\hline $\begin{array}{l}\text { Elementary or } \\
\text { middle school }\end{array}$ & $4(11.8)$ & & \\
\hline High school & $20(58.8)$ & & \\
\hline College & $10(29.4)$ & & \\
\hline Time in U.S. (y) & & $28.4 \pm 16.0$ & $30.0(31.0)$ \\
\hline Age (y) & & $37.6 \pm 9.5$ & $38.5(16.0)$ \\
\hline Weight (kg) & & $79.9 \pm 17.9$ & $77.2(26)$ \\
\hline $\begin{array}{l}\text { Body mass } \\
\text { index }\left(\mathrm{kg} / \mathrm{m}^{2}\right)\end{array}$ & & $29.1 \pm 5.7$ & $29.2(7.2)$ \\
\hline Waist circumference $(\mathrm{cm})$ & & $96.5 \pm 14.2$ & $95.3(18.0)$ \\
\hline Hip circumference (cm) & & $108.9 \pm 11.7$ & $107.8(15.0)$ \\
\hline Body fat (\%) & & $34.1 \pm 9.2$ & $34.1(13.8)$ \\
\hline $\begin{array}{l}\text { Systolic blood pressure } \\
(\mathrm{mm} \mathrm{Hg})\end{array}$ & & $114.4 \pm 12.1$ & $112.8(17.0)$ \\
\hline $\begin{array}{l}\text { Diastolic blood } \\
\text { pressure }(\mathrm{mm} \mathrm{Hg})\end{array}$ & & $72.3 \pm 9.2$ & $73.5(12.0)$ \\
\hline MVPA $\left(\min \cdot w k^{-1}\right)$ & & $153.3 \pm 88.8$ & $140.0(105.0)$ \\
\hline $\begin{array}{l}\text { Meeting U.S. } \\
\text { PA guidelines' }\end{array}$ & $15(48)$ & & \\
\hline
\end{tabular}

${ }^{1}$ Based on accelerometer MVPA.

were female (62\%), bilingual in English and Spanish (88\%), and were born in the U.S. (56\%). Mean residence time in the U.S. was $28.4 \pm 16.0$ y. Participants' mean BMI was $29.1 \pm 5.7 \mathrm{~kg} / \mathrm{m}^{2} ; 26 \%$ of participants were classified as being overweight and $44 \%$ of participants were classified as being obese. All participants had normal blood 
pressure (systolic blood pressure $=114.4 \pm 12.1 \mathrm{~mm} \mathrm{Hg}$; diastolic blood pressure $=72.3 \pm 9.2 \mathrm{~mm} \mathrm{Hg}$ ).

\section{Participants' physical activity patterns}

Participants' mean accelerometer wear time was $12.0 \pm$ 2.3 hours $^{\bullet} \mathrm{d}^{-1}$. Based on accelerometer assessment of activity mean MVPA was $153 \pm 89 \mathrm{~min} \bullet \mathrm{wk}^{-1}$ (Table 1 ). Figure 1 illustrates the amount of objectively-measured MVPA for participants that were classified into each survey-assessed PA category. According to SBAS categories, mean MVPA (in min ${ }^{*} \mathrm{k}^{-1}$ ) for participants classified to the inactive, light, moderate, hard, and very hard categories were $94 \pm 74(n=3), 145 \pm 64(n=10), 104 \pm 41$ $(\mathrm{n}=5), 183 \pm 74(\mathrm{n}=7)$, and $234 \pm 137(\mathrm{n}=5)$, respectively. According to RAPA categories, mean MVPA (in min $\bullet \mathrm{wk}^{-1}$ ) for participants classified into the underactive, regular underactive light, regular underactive, and regular active categories were $115 \pm 4(n=2), 94 \pm 72(n=3), 123 \pm 65$ $(\mathrm{n}=11)$, and $192 \pm 99(\mathrm{n}=15)$, respectively.

Fifteen of 31 (48\%) of participants met the U.S. PA guidelines of $\geq 150 \mathrm{~min} \bullet \mathrm{wk}^{-1}$ of MVPA [41]. Participants

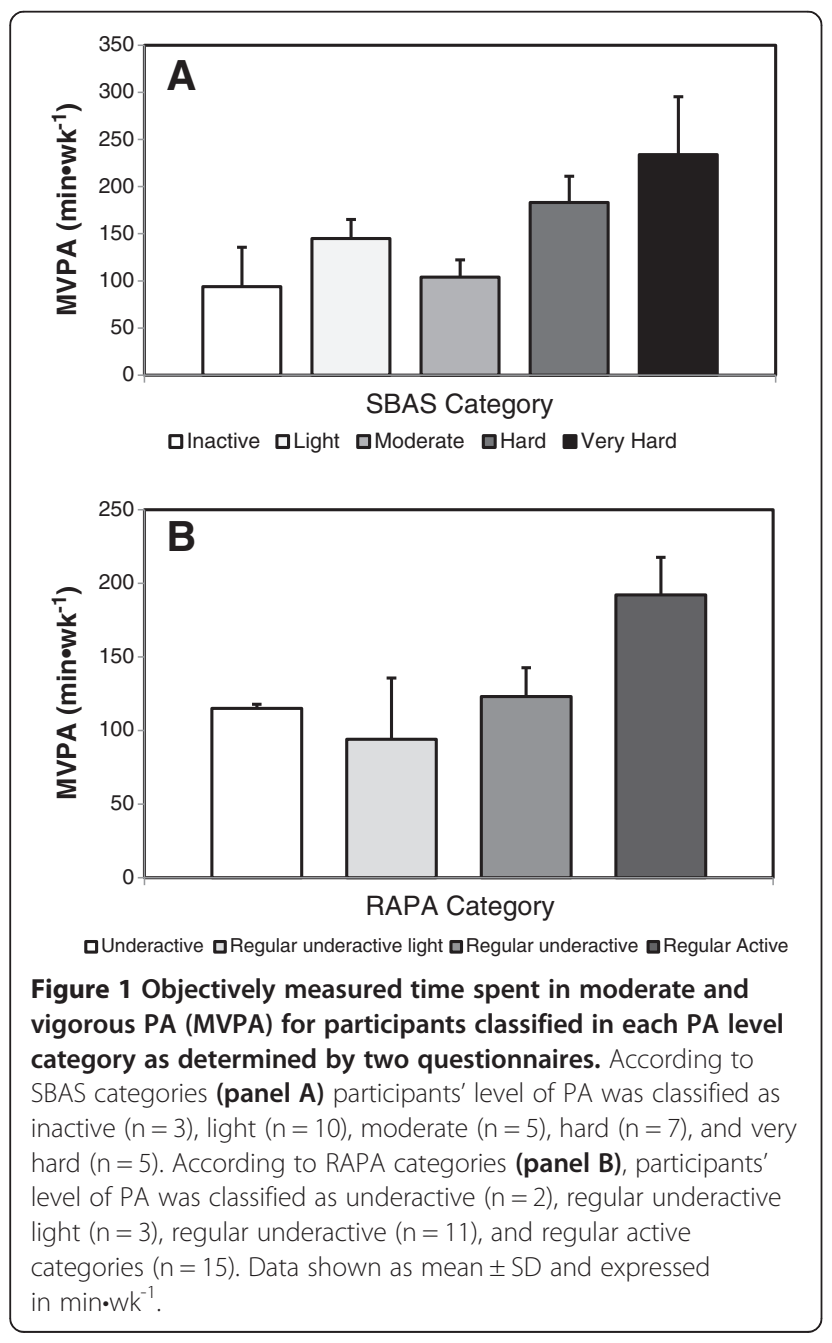

classified as meeting the 2008 U.S. PA guidelines based on SBAS PA level spent $42 \mathrm{~min}^{\bullet} \mathrm{wk}^{-1}$ engaged in MVPA more than those classified as not meeting the guidelines, this difference was not statistically significant (Table 2). When using the RAPA to classify participants based on their compliance with the 2008 U.S. PA guidelines, those who were classified as meeting the guidelines spent significantly more time engaged in MVPA than those who did not meet the guidelines $\left(192 \pm 99 \mathrm{~min}^{\circ} \mathrm{wk}^{-1}\right.$ of MVPA vs. $117 \pm 61 \mathrm{~min} \cdot \mathrm{wk}^{-1}$ of MVPA, respectively; $p=0.018)$.

\section{Survey validation}

Validity and test-retest reliability for the SBAS were 0.38 $(p<0.05)$ and $0.61(p<0.01)$, respectively (Table 3$)$. The SBAS had sensitivity, specificity, and positive and negative predictive values of $0.60,0.47,0.53$, and 0.54 , respectively.

Validity and test-retest reliability for the RAPA were $0.45(p<0.05)$ and $0.65(p<0.01)$, respectively. The RAPA had sensitivity, specificity, and positive and negative predictive values of $0.73,0.75,0.73$, and 0.75 , respectively.

\section{Discussion}

The purpose of this work was to explore the utility of the Mexican Spanish version of two questionnaires, the Stanford Brief Activity Survey (SBAS) and the Rapid Assessment of Physical Activity (RAPA), for use as tools to assess PA in Mexican-American adults.

\section{Validity and test-retest reliability}

Both questionnaires showed modest validity compared with ActiGraph accelerometer objective measures of PA $(\mathrm{r}=0.38$ and 0.45 for the SBAS and the RAPA, respectively). Relative to the English version of the SBAS [30], the validity of the Spanish version was lower. One plausible explanation may be the long activity descriptions and lack of cultural relevance in the types of activities given as examples for leisure time and occupational physical activities. This demonstrates the necessity for implementing cultural adaptations when translating physical activity questionnaires to be delivered to the Hispanic population. In the previous validation study of the English version of the SBAS [30,37] participants were aged 60-69, of mixed race, and many had hypertension (60\%), hyperlipidemia (45\%), metabolic syndrome (26\%), or type 2 diabetes (18\%). In contrast, participants in the current study were younger and were a more homogenous group as all were Hispanic and none had diagnosis of chronic diseases. This difference in study population may have contributed to the limited distribution of participants among the different categories of PA. In contrast, validity of the Spanish version of the RAPA 
Table 2 Time (in min•wk ${ }^{-1}$ ) spent engaged in MVPA when participants were classified as meeting or not meeting the 2008 U.S. PA guidelines assessed using accelerometer, the SBAS, and the RAPA ${ }^{1}$

\begin{tabular}{|c|c|c|c|c|c|}
\hline \multirow[t]{2}{*}{ Assessment method } & \multicolumn{2}{|c|}{ Meeting guidelines } & \multicolumn{2}{|c|}{ Not meeting guidelines } & \multirow[t]{2}{*}{$p$ value } \\
\hline & $\bar{n}$ & Time $\left(\min \cdot w^{-1}\right)$ & $n$ & Time $\left(\min \cdot w^{-1}\right)$ & \\
\hline Accelerometers & 15 & $221 \pm 75$ & 16 & $90 \pm 39$ & 0.0001 \\
\hline SBAS & 17 & $175 \pm 100$ & 13 & $133 \pm 66$ & 0.222 \\
\hline RAPA & 15 & $192 \pm 99$ & 16 & $117 \pm 61$ & 0.018 \\
\hline
\end{tabular}

${ }^{1}$ Data shown as mean \pm SD and expressed in $\min \cdot \mathrm{wk}^{-1}$; MVPA: Moderate Walking + Vigorous PA.

${ }^{2} \mathrm{P}$-value for independent $\mathrm{t}$-test performed on the square root transformation of MVPA for those meeting and not meeting the 2008 U.S. PA guidelines.

was of comparable magnitude to that reported for its English version [31]. It must be noted that the studies validating the English version of both questionnaires used a subjective measure of PA for comparison [30,31], whereas the current study used an objective measure of PA. Previous research comparing subjective measures of PA to objective measures reported modest Spearman rank order correlation coefficients of similar magnitude to those reported herein [42]. Moreover, with this approach we were able to demonstrate the concurrent validity of these questionnaires for assessing both, meeting or not meeting the 2008 PA Guidelines [41].

Test-retest reliability was modest when the Spanish version of the surveys was administered in duplicate one week apart (ICC $=0.61$ and 0.65 for the SBAS and the RAPA, respectively). Validation studies for the original English version of these surveys did not report testretest reliability. However, when the English SBAS was administered 2 years apart in participants assigned to the control group of an intervention study; the scores from both assessments were significantly correlated $(\mathrm{r}=0.62, p<0.001)$ [37].

The values that we obtained were comparable to previous validation studies in this population. For example Rauh et al. [43] reported weak to moderate correlations between five self-reported measures of PA and counts obtained using an electronic motion sensor in a sample of Latinos, most of Mexican descent. These surveys also had variable test-retest reliability. In a separate study, the Yale Physical Activity Survey had moderate to good reliability for estimating energy expenditure, and energy spent in select specific activities (shopping, light housework, food preparation) [44]. This suggests that, despite the population age or the type of instrument used, translations into Spanish and completion by Hispanic individuals may involve differences in how the respondents understand the questions as written and intent of the questions asked. However, due to our small sample size $(\mathrm{n}=31$ RAPA; $\mathrm{n}=30$ SBAS) the conclusions drawn from these data must be interpreted with caution.

\section{Sensitivity, specificity, PPV, and NPV}

Sensitivity and specificity of the Spanish SBAS were 0.60 and 0.47 , respectively. Whereas these values are lower than those determined in the previous validation study with the English version of the SBAS (0.73 and 0.61 for sensitivity and specificity, respectively) in different populations [30], the current study used an objective measure to determine weekly minutes of PA rather than a survey. This indicates the ability of the SBAS to accurately identify those who meet the PA recommendations is better than chance (at 0.50). However no significant differences in minutes of MVPA were observed between those classified as meeting and not meeting the PA guidelines by the SBAS. The low specificity suggests the SBAS may misclassify participants who do not meet the PA guidelines. Furthermore, only $29 \%$ of participants in our sample reported not having a job; in the previous validation study with the English SBAS [30] 50\% of participants reported no work. This major difference in sample population could also explain why the SBAS did not perform as well with our population, as it did in previous validation studies [30,37]. We selected the SBAS because it has been previously validated and it includes an assessment of occupational PA. Previous research has highlighted the need for capturing this domain of physical activity, as Mexicans engage in occupational PA

Table 3 Validity, test-retest reliability, sensitivity, specificity, positive and negative predictive values of the Mexican Spanish version of the SBAS and the RAPA compared to accelerometer-measured MVPA

\begin{tabular}{lcccccc}
\hline & \multicolumn{2}{c}{ SBAS } & & \multicolumn{2}{c}{ RAPA } \\
\cline { 2 - 3 } \cline { 5 - 6 } & & $\mathbf{r}$ & $\boldsymbol{p}$ value & & $\mathbf{r}$ & $\boldsymbol{p}$ value \\
\hline Validity $^{1}$ & 0.38 & 0.04 & & 0.45 & 0.01 \\
& ICC & $\boldsymbol{p}$ value & & ICC & $\boldsymbol{p}$ value \\
Test-retest reliability $^{2}$ & 0.61 & 0.005 & & 0.65 & 0.002 \\
Sensitivity $^{3}$ & & 0.60 & & & 0.73 \\
Specificity $^{4}$ & & 0.47 & & & 0.75 \\
Positive predictive value $^{5}$ & & 0.53 & & & 0.73 \\
Negative predictive value $^{6}$ & & 0.54 & & & 0.75
\end{tabular}

${ }^{1}$ Spearman's rank ordered correlation between MVPA and score on each questionnaire.

${ }^{2}$ Intraclass Correlation Coefficient between the scores on the first and second administration of each questionnaire administered one week apart.

${ }^{3}$ True positives/ (true positives + false negatives).

${ }^{4}$ True negatives/ (true negatives + false positives).

${ }^{5}$ True positives/ all positives.

${ }^{6}$ True negatives/ all negatives. 
more frequently than other ethnic groups [22]. However, it is possible that many of the activities included in this survey may lack cultural relevance for Spanish speaking individuals of Mexican descent.

Sensitivity and specificity were 0.73 and 0.75 , respectively, for the RAPA. These values are comparable to the validation of the English version of the RAPA in different populations (0.82 and 0.69 , respectively) [30,31]. Participants classified as meeting the PA guidelines by the RAPA engaged in 64\% more time in MVPA than those who were classified as not meeting the guidelines $(p=0.018)$. The specificity of the RAPA was slightly higher than the SBAS, indicating better discrimination than the SBAS in correctly classify those who do not meet the 2008 PA guidelines by the questionnaire and accelerometry.

Positive and negative predictive values for both studies were comparable to those values obtained in previous validation studies [30,31]. Positive predictive value and negative predictive value was lower for the SBAS than the RAPA, indicating the RAPA questionnaire is better at discriminating between those who do and do not meet the PA guidelines from the questionnaire. However, an important limitation that must be acknowledged is the relatively small sample size $(n=31$, RAPA; $n=30$, SBAS) for this type of validation study, which may have reduced the statistical power to detect if the scores from these questionnaires are useful to identify participants who participate in different levels of MVPA, and may have affected the intraclass correlation coefficients used to determine test-retest reliability.

It is noteworthy that participants in the current study had a higher level of MVPA $\left(153.3 \pm 38.8 \mathrm{~min}^{\bullet} \mathrm{wk}^{-1}\right)$ than what has been previously reported in the literature [45]. By study design, we attempted to recruit participants with diverse physical activity habits, which may have led to the inclusion of some participants who were regularly highly active. Nevertheless, only a small proportion of MVPA time was spent in vigorous activity (10.4 \pm $24.3 \mathrm{~min} \cdot \mathrm{wk}^{-1}$ ) which suggests that the majority of the participants were likely not regular heavy exercisers, but instead engaged in a high level of health enhancing moderate-intensity physical activity.

The use of accelerometers for assessing PA was an important strength of this study, as previous validation studies compared newly developed self-report questionnaires to other self-report measures [30,31]. The current study also has limitations worth acknowledging. The small sample size limited the statistical power and the ability to make any definitive conclusions regarding observed results from this study. Given the heterogeneity within the study sample (wide range in age, time in the US, education, etc.) it is possible that factors not accounted for in this analysis may limit the generalizability of the results reported herein. It is also important to acknowledge that the selected questionnaires are not meant to be used for the assessment of changes in physical activity over time, but rather as a quick screening tool to be used in clinical settings or for the collection of epidemiological data. Finally, although participants were asked to maintain their level of physical activity throughout the duration of the study, the possibility that participants were more active during the week of data collection cannot be ruled out.

\section{Conclusions}

Data from the current study demonstrate the modest ability of the Spanish translated versions of the SBAS and RAPA to predict PA levels. Both questionnaires demonstrated acceptable validity, reliability, specificity, sensitivity, and predictive values against an objective measure of PA. In light of reported discrepancies in PA levels of Mexican Americans based on the type of assessment method used $[19,20,33,45]$ there are recent recommendations to culturally adapt translated surveys to ensure the equivalence and cultural relevance of listed items among the target population [46]. Formative research for the cultural adaptation of these instruments, particularly the SBAS, and inclusion of activities that more closely reflect those in which individuals of Mexican descent engage, such as those of occupational nature [22], would prove beneficial.

\section{Abbreviations}

BMI: Body mass index; Cpm: Counts per minute; ICC: Intraclass correlation coefficients; MVPA: Moderate and vigorous physical activity; NPV: Negative predictive value; PPV: Positive predictive value; RAPA: Rapid Assessment of Physical Activity; SBAS: Stanford Brief Activity Survey; SLML: Sedentary, light, and moderate lifestyle.

\section{Competing interests}

The authors have no financial competing interests to declare.

\section{Authors' contributions}

SVL was responsible for study design, oversight of data collection and analysis, data interpretation, and manuscript preparation. AC carried out data analysis and contributed to manuscript preparation. KJF participated in study coordination and data collection. BEA assisted with study design, data analysis and interpretation, and manuscript preparation. All authors read and approved the final manuscript.

\section{Acknowledgements}

The authors would like to acknowledge Dr. Stephen Herrmann, Postdoctoral Fellow, University of Kansas Medical Center, for his assistance with accelerometer data collection.

Received: 19 August 2013 Accepted: 8 January 2014 Published: 13 January 2014

\section{References}

1. U.S. Census Bureau; American FactFinder: DP-1 Profile of general population and housing characteristics: 2010 demographic profile data. Available at: http://factfinder2.census.gov/faces/tableservices/jsf/pages/ productview.xhtml?src=bkmk. Accessed on June 18, 2012.

2. Bates $L M$, Acevedo-Garcia D, Alegria M, Krieger N: Immigration and generational trends in body mass index and obesity in the United States: results of the National Latino and Asian American Survey, 2002-2003. Am J Public Health 2008, 98:70-77. 
3. Pan L, Galuska DA, Sherry B, Hunter AS, Rutledge GE, Dietz WH, Balluz LS: Differences in prevalence of obesity among Black, White and Hispanic adults-United States, 2006-2008. Morb Mortal Wkly Rep 2009, 27:740-744

4. Wang Y, Beydoun MA: The obesity epidemic in the United States: gender, age, socioeconomic, racial/ethnic, and geographic characteristics: a systematic review and meta-regression analysis. Epidemiol Rev 2007, 29:6-28.

5. Kurian A, Cardarelli K: Racial and ethnic differences in cardiovascular disease risk factors: a systematic review. Ethn Dis 2007, 17:143-152.

6. Kelley-Hedgepeth A, Lloyd-Jones DM, Colvin A, Matthews KA, Johnston J, Sowers MR, Sternfeld B, Pasternak RC, Chae CU, for the SWAN Investigators: Ethnic differences in C-reactive protein concentrations. Clin Chem 2008, 54:1027-1037.

7. Wee CC, Mukamal KJ, Huang A, Davis RB, McCarthy EP, Mittleman MA: Obesity and C-reactive protein levels among White, Black, and Hispanic US adults. Obesity 2008, 16:875-880.

8. Ong KL, Cheung BMY, Wong LYF, Wat NMS, Tan KCB, Lam KSL: Prevalence, treatment, and control of diagnosed diabetes in the U.S. National Health and Nutrition Examination Survey 1999-2004. Ann Epidemiol 2008, 18:222-229.

9. Ford ES, Giles WH, Dietz WH: Prevalence of the metabolic syndrome among US adults: findings from the Third National Health and Nutrition Examination Survey. JAMA 2002, 287:356-359.

10. Cowie CC, Rust KF, Byrd-Holt DD, Eberhardt MS, Flegal KM, Engelgau MM, Saydah SH, Williams DE, Geiss LS, Gregg EW: Prevalence of diabetes and impaired fasting glucose in adults in the U.S. population: National Health and Nutrition Examination Survey 1999-2002. Diabetes Care 2006, 29:1263-1268

11. Cowie CC, Rust KF, Ford ES, Eberhardt MS, Byrd-Holt DD, Li C, Williams DE, Gregg EW, Bainbridge KE, Saydah SH, Geiss LS: Full accounting of diabetes and pre-diabetes in the U.S. population in 1988-1994 and 2005-2006. Diabetes Care 2009, 32:287-294.

12. Physical Activity Guidelines Advisory Committee: Physical activity guidelines advisory committee report, 2008. In Book Physical activity guidelines advisory committee report, 2008. City: U.S. Government Printing Office; 2008

13. Oguma Y, Sesso H, Paffenbarger RS Jr, Lee I: Physical activity and all cause mortality in women: a review of the evidence. Br J Sports Med 2002, 36:162-172.

14. Paffenbarger RS Jr, Hyde R, Wing AL, Hsieh C-C: Physical activity, all-cause mortality, and longevity of college alumni. N Engl J Med 1986, 314:605-613.

15. Laaksonen DE, Lindström J, Lakka TA, Eriksson JG, Niskanen L, Wikström K, Aunola S, Keinänen-Kiukaanniemi S, Laakso M, Valle T, et al: Physical activity in the prevention of type 2 diabetes: the Finnish diabetes prevention study. Diabetes 2005, 54:158-165.

16. Sesso H, Paffenbarger RS Jr, Lee I-M: Physical activity and coronary heart disease in men: the Harvard alumni health study. Circulation 2000, 102:975-980.

17. Haskell WL, Lee I-M, Pate RR, Powell KE, Blair SN, Franklin BA, Macera CA, Heath GW, Thompson PD, Bauman A: Physical activity and public health: updated recommendation for adults from the American College of Sports Medicine and the American Heart Association. Circulation 2007, 116:1081-1093.

18. Carlson SA, Fulton JE, Schoenborn CA, Loustalot F: Trend and prevalence estimates based on the 2008 physical activity guidelines for Americans. Am J Prev Med 2010, 39:305-313.

19. Slattery ML, Sweeney C, Edwards S, Herrick J, Murtaugh M, Baumgartner K, Guilliano A, Byers T: Physical activity patterns and obesity in Hispanic and non-Hispanic white women. Med Sci Sports Exerc 2006, 38:33-41.

20. Carnethon MR, Gulati M, Greenland P: Prevalence and cardiovascular disease correlates of low cardiorespiratory fitness in adolescents and adults. JAMA 2005, 294:2981-2988.

21. Westerterp KR: Assessment of physical activity: a critical appraisal. Eur J Appl Physiol 2009, 105:823-828.

22. Marquez DX, Neighbors CJ, Bustamante EE: Leisure time and occupational physical activity among racial or ethnic minorities. Med Sci Sports Exerc 2010, 42:1086-1093.

23. Ayala GX, Gammelgard A, Sallis JF, Elder JP: The association of physical activity and work-related characteristics among Latino adults. J Phys Act Health 2011, 8:79-84.

24. Elosua R, Marrugat J, Molina L, Pons S, Pujol E: Validation of the Minnesota leisure time physical activity questionnaire in Spanish men. Am J Epidemiol 1994, 139:1197-1209.
25. Martínez-González MA, López-Fontana C, Varo JJ, Sánchez-Villegas A, Martinez JA: Validation of the Spanish version of the physical activity questionnaire used in the nurses' health study and the health professionals' follow-up study. Public Health Nutr 2005, 8:920-927.

26. Roman-Viñas B, Serra-Majem L, Hagstromer M, Ribas-Barba L, Sjostrom M, Segura-Cardona R: International physical activity questionnaire: reliability and validity in a Spanish population. Euro J Sport Sci 2010, 10:297-304.

27. Martinez SM, Ainsworth BE, Elder JP: A review of physical activity measures used among US Latinos: guidelines for developing culturally appropriate measures. Ann Behav Med 2008, 36:195-207.

28. Poston WSC, Haddock K, Suminski RR, Olvera NE: Evaluation of a culturally appropriate intervention to increase physical activity. Am J Health Behav 2001, 25:396.

29. Shephard R, Vuillemin A: Limits to the measurement of habitual physical activity by questionnaires: commentary. Br J Sports Med 2003, 37:197-206.

30. Taylor-Piliae RE, Norton LC, Haskell WL, Mahbouda MH, Fair JM, Iribarren C, Hlatky MA, Go AS, Fortmann SP: Validation of a new brief physical activity survey among men and women aged 60-69 years. Am J Epidemio/ 2006, 164:598-606.

31. Topolski T, LoGerfo J, Patrick D, Williams B, Walwick J, Patrick M: The Rapid Assessment of Physical Activity (RAPA) among older adults. Prev Chronic Dis 2006, 3:A118.

32. Plasqui G, Westerterp KL: Physical activity assessment with accelerometers: an evaluation against doubly labeled water. Obesity 2007, 15:2371-2379

33. Matthews CE, Chen KY, Freedson PS, Buchowski MS, Beech BM, Pate RR, Troiano RP: Amount of time spent in sedentary behaviors in the United States, 2003-2004. Am J Epidemiol 2008, 167:875-881.

34. Matthews CE, Ainsworth B, Hanby C, Pate R, Addy C, Freedson P, Jones D, Macera $C$ : Development and testing of a short physical activity recall questionnaire. Med Sci Sports Exerc 2005, 37:986-994.

35. Freedson P, Melanson E, Sirard J: Calibration of the computer science and application: Inc. accelerometer. Med Sci Sports Exerc 1998, 30:777-781.

36. Matthews CE, Ainsworth BE, Thompson RW, Bassett DR Jr: Sources of variance in daily physical activity levels as measured by an accelerometer. Med Sci Sports Exerc 2002, 34:1376-1381.

37. Taylor-Piliae RE, Fair J, Haskell W, Varady A, Iribarren C, Hlatky M, Go A, Fortmann S: Validation of the Stanford brief activity survey: examining psychological factors and physical activity levels in older adults. J Phys Act Health 2010, 7:87-94.

38. Marin G, Marin BV: Research with Hispanic populations: Applied Social Research Methods Series. Vol. 23. Newberry Park, CA: SAGE Publications, Inc; 1991.

39. Stewart AL, Mills KM, King AC, Haskell WL, Gillis D, Ritter PL: CHAMPS physical activity questionnaire for older adults: outcomes for interventions. Med Sci Sports Exerc 2001, 33:1126-1141.

40. Patrick K, Sallis JF, Long B, Calfas KJ, Wooten W, Heath GW, Pratt M: A new tool for encouraging physical activity: project PACE. Phys Sportsmed 1994, 22:45-55.

41. U.S. Department of Health and Human Services: Physical Activity Guidelines for Americans, 2008. Washington, DC: U.S. Government Printing Office; 2008

42. Miller DJ, Freedson PS, Kline GM: Comparison of activity levels using the Caltrac accelerometer and five questionnaires. Med Sci Sports Exerc 1994, 26:376-382.

43. Rauh MJD, Hovell MF, Hofstetter CR, Sallis JF, Gleghorn A: Reliability and validity of self-reported physical activity in Latinos. Int J Epidemiol 1992, 21:966-971.

44. Pennathur A, Magham R, Contreras LR, Dowling W: Test-retest reliability of yale physical activity survey among older Mexican American adults: a pilot investigation. Exp Aging Res 2004, 30:291-303.

45. Troiano RP, Berrigan D, Dodd KW, Mâsse LC, Tilert T, McDowell MA: Physical activity in the United States measured by accelerometer. Med Sci Sports Exerc 2008, 40:181-188

46. Arredondo EM, Mendelson T, Holub C, Espinoza N, Marshall S: Cultural adaptation of physical activity self-report instruments. J Phys Act Health 2012, 9:\$37-S43.

doi:10.1186/1756-0500-7-29

Cite this article as: Vega-López et al:: Validity and reliability of two brief physical activity questionnaires among Spanish-speaking individuals of Mexican descent. BMC Research Notes 2014 7:29. 